\title{
An Environmental Friendly Procedure for Photometric Determination of Hypochlorite in Tap Water Employing a Miniaturized Multicommuted Flow Analysis Setup
}

\author{
Sivanildo S. Borges ${ }^{1}$ and Boaventura F. Reis ${ }^{2}$ \\ ${ }^{1}$ Centro de Ciências Exatas e Tecnológicas, Universidade Federal do Recôncavo da Bahia, Centro, \\ 44380-000 Cruz das Almas BA, Brazil \\ ${ }^{2}$ Centro de Energia Nuclear na Agricultura, Universidade de São Paulo, Avenida Centenário, 303 São Dimas,
} 13400970 Piracicaba SP, Brazil

Correspondence should be addressed to Boaventura F. Reis, reis@cena.usp.br

Received 6 October 2010; Revised 7 March 2011; Accepted 9 March 2011

Academic Editor: Jaroon Jakmunee

Copyright ( $) 2011$ S. S. Borges and B. F. Reis. This is an open access article distributed under the Creative Commons Attribution License, which permits unrestricted use, distribution, and reproduction in any medium, provided the original work is properly cited.

\begin{abstract}
A photometric procedure for the determination of $\mathrm{ClO}^{-}$in tap water employing a miniaturized multicommuted flow analysis setup and an LED-based photometer is described. The analytical procedure was implemented using leucocrystal violet (LCV; $4,4^{\prime}, 4^{\prime \prime}-$ methylidynetris (N,N-dimethylaniline), $\mathrm{C}_{25} \mathrm{H}_{31} \mathrm{~N}_{3}$ ) as a chromogenic reagent. Solenoid micropumps employed for solutions propelling were assembled together with the photometer in order to compose a compact unit of small dimensions. After control variables optimization, the system was applied for the determination of $\mathrm{ClO}^{-}$in samples of tap water, and aiming accuracy assessment samples were also analyzed using an independent method. Applying the paired $t$-test between results obtained using both methods, no significant difference at the $95 \%$ confidence level was observed. Other useful features include low reagent consumption, $2.4 \mu \mathrm{g}$ of LCV per determination, a linear response ranging from 0.02 up to $2.0 \mathrm{mg} \mathrm{L}^{-1} \mathrm{ClO}^{-}$, a relative standard deviation of $1.0 \%(n=11)$ for samples containing $0.2 \mathrm{mg} \mathrm{L}^{-1} \mathrm{ClO}^{-}$, a detection limit of $6.0 \mu \mathrm{g} \mathrm{L}^{-1} \mathrm{ClO}^{-}$, a sampling throughput of 84 determinations per hour, and a waste generation of $432 \mu \mathrm{L}$ per determination.
\end{abstract}

\section{Introduction}

Since the use of chlorine for tap water treatment was adopted in England in the 1880s [1], water chlorination has been one of the most common disinfectant methods used by waters suppliers [2]. Because chlorine is an efficient agent for inactivating several types of microorganisms, it has been preferred as a disinfecting agent to assure the bacteriological quality of the drinking water [3]. The water bacterial contamination can also occur in the distribution network; therefore, to prevent this occurrence, a free chlorine residual in excess of $0.2 \mathrm{mg} \mathrm{L}^{-1}$ must be maintained throughout the distribution lines $[3,4]$. Therefore, the availability of sensitive and reliable analytical procedure for chlorine determination can be considered as an essential condition to assure the quality of tap water. Determination of free chloride in tap water has been carried out by employing as detection techniques amperometry [5], spectrophotometry [6], ion selective electrode [7], chemiluminescence [8], and so forth.

In this work, we intend to develop a photometric procedure for the determination of residual chlorine in tap water using leuco crystal violet (LCV; 4,4', $4^{\prime \prime}$-methylidynetris (N,N-dimethylaniline), $\mathrm{C}_{25} \mathrm{H}_{31} \mathrm{~N}_{3}$ ) as chromogenic reagent. LCV is colorless in aqueous solution, but when oxidized at $\mathrm{pH} 4$, it forms crystal violet dye $\left(\mathrm{CV}^{+}\right)$, which absorbs electromagnetic radiation with a maximum at $592 \mathrm{~nm}[9,10]$. LCV has been employed in procedures for the determination of hydrogen peroxide [11], iodine, iodide and hypoiodous acid $[9,12,13]$, iridium [14], and oxidized manganese [10]. Although, LCV has been widely used in analytical procedures, it has not yet been used for hypochlorite determination, which will be attempted in this investigation. 
Nowadays, efforts have been made to environmentally friendly develop analytical procedures, and thus accomplishing the Green Analytical Chemistry (GAC) recommendation [15-17]. Reduction of reagent consumption and waste generation are among the requisites necessary to attain the GAC recommendation [18, 19]. Multicommuted flow analysis (MCFA) [20-22] and multisyringe flow injection analysis (MSFIA) $[18,23]$ are efficient tools for handling low volumes of sample and reagent solutions, thus providing facilities to save them. Solenoid minipumps have been employed to propel solution in flow analysis systems replacing the peristaltic pump, presenting as an advantage small dimension [24-26], a feature that has been exploited in order to downscale the flow system $[27,28]$. This downscaling approach seems to be a powerful tool to develop analytical procedure focused to the GAC recommendation. In the research reported here, these features are exploited to design a miniaturized flow system setup based on the MCFA process for photometric determination of hypochlorite in tap water.

\section{Experimental}

2.1. Reagents Solutions. All chemicals were of analyticalgrade reagent. Purified water with electric conductivity lower than $0.1 \mu \mathrm{S} \mathrm{cm}^{-1}$ was used throughout.

An acetate buffer solution $\left(0.2 \mathrm{~mol} \mathrm{~L}^{-1}\right)$ was prepared by dissolving $1.6408 \mathrm{~g}$ of sodium acetate in $20 \mathrm{~mL}$ of water. After dissolution, $\mathrm{pH}$ was adjusted to 4.0 using a $2.0 \mathrm{~mol} \mathrm{~L}^{-1}$ $\mathrm{HCl}$ solution. Afterwards, the volume was made up to $100 \mathrm{~mL}$ with water. A $1.0 \mathrm{~g} \mathrm{~L}^{-1}$ leuco crystal violet (LCV; $4,4^{\prime}, 4^{\prime \prime}$-methylidynetris (N,N-dimethylaniline), $\mathrm{C}_{25} \mathrm{H}_{31} \mathrm{~N}_{3}$ ) stock solution was prepared by dissolving $0.1 \mathrm{~g}$ of solid material (Eastman Kodak) in $1 \mathrm{~mL}$ of phosphoric acid (Merck) 85\% (v/v). After dissolution, the volume was made up to $100 \mathrm{~mL}$ with water. A $0.1 \mathrm{~g} \mathrm{~L}^{-1} \mathrm{LCV}$ working solution was prepared daily by adequate dilution of the stock solution with water.

A $1000 \mathrm{mg} \mathrm{L}^{-1}$ hypochlorite $\left(\mathrm{ClO}^{-}\right)$stock solution was prepared by adequate dilution of a $10 \%(\mathrm{w} / \mathrm{v})$ reagent solution (Fluka) in $100 \mathrm{~mL}$ of a $0.01 \mathrm{~mol} \mathrm{~L}^{-1} \mathrm{NaOH}$ solution. This solution was standardized using the iodometric titration method [29]. Hypochlorite working solutions ranging from 0.02 up to $2.0 \mathrm{mg} \mathrm{L}^{-1}$ were prepared daily by adequate dilution of the $\mathrm{ClO}^{-}$stock solution using a $10^{-4} \mathrm{~mol} \mathrm{~L}^{-1}$ $\mathrm{NaOH}$ solution.

A set of tap water samples was collected from several points of Piracicaba City. Prior to analysis, samples were alkalized by adding $1.0 \mathrm{~mL}$ of a $10^{-1} \mathrm{~mol} \mathrm{~L}^{-1} \mathrm{NaOH}$ solution to a volumetric flask, and the volume was made up to $100 \mathrm{~mL}$ with sample.

2.2. Equipment. The apparatus included a microcomputer running a software written in QuicH BASIC 4.5, a digital multimeter with a serial interface (Minipa, ET-2231), three solenoid minipumps (Bio-Chem Valve Inc., 090SP115-8), a homemade interface to drive the solenoid pumps [30], which was coupled to the microcomputer through the parallel output port, a homemade regulated power supply $(-12 \mathrm{~V}$, $+12 \mathrm{~V})$ to feed the photometer, an orange high-bright LED $(\lambda=590 \mathrm{~nm})$, and a photodiode OPT301 (Burr Brawn). A homemade flow cell machined in acrylic, with an optical path length of $20 \mathrm{~mm}$ and an inner diameter of $1.0 \mathrm{~mm}$, and a homemade bubble-removing microdevice machined in acrylic, with an inner volume of $10 \mu \mathrm{L}$, was similar to that used elsewhere [28]. All flow lines were of Tygon tubing with $0.56 \mathrm{~mm}$ inner diameters. The system control and data acquisition were performed by the microcomputer, running software written in Quick BASIC 4.5.

2.3. Analytical Procedure. The diagram of the proposed setup is shown in Figure 1. The network constituted by a transistor ( Te), and resistors were used to control the intensity of the light beam emitted by the LED. The glass cylinders $(g)$ conducted the light beams $I_{1}$ and $I_{2}$ from the LED up to the flow cell channel, and from there up to the photodetector (Det), respectively. When the software was run, the solenoid minipumps $P_{1}, P_{2}$, and $P_{3}$ were switched in an alternating On/Off sequence, as shown in Table 1, so as to fill each flow line with the respective solution. Afterwards, mini-pump $P_{2}$ was switched On/Off 40 times to wash the flow cell with carrier solution. The calibration step included the reading of both the dark signal $\left(D_{k}\right)$ and the reference signal $\left(S_{s}\right)$. In the first case, the reading was done with LED switched Off while, in the second one, the LED emission was enabled by turning forward the variable resistor $(10 \mathrm{k} \Omega$ ) wired to the base of the transistor ( $\mathrm{Tr}$ ). The emission intensity was adjusted to obtain an electric potential difference $\left(S_{s}\right)$ of $2000 \mathrm{mV}$ generated by the photodetector (Det). The measurements $D_{k}$ and $S_{s}$ were converted to digital signal by the multimeter and sent to the microcomputer through the serial interface. These measurements were used for the absorbance calculation.

A micropumping On/Off switching event is named as a sampling cycle, thus the volumes of sample and reagents solutions necessary to carry out the analysis were found by varying the number of sampling cycles. As shown in Table 1 (step d), micro-pumps $P_{1}$ and $P_{2}$ were switched simultaneously, so that the coil $\left(B_{1}\right)$ was loaded with a mixture of reagent and buffer solutions. Afterwards (step e), micropumps $P_{2}$ and $P_{3}$ were switched On/Off also simultaneously, so that slugs of the sample and a mixture of buffer and reagent solutions merged into the coil $\left(B_{2}\right)$. The reaction for forming the compound to be monitored proceeded while the sample zone was displaced towards the photodetector (Det). While steps (d) and (f) were performed, the microcomputer carried out data acquisition and saved this data as an ASCII file, to allow further processing. The absorbance was calculated using the following equation: Absorb $=-\log \left[\left(S_{0}-\right.\right.$ $\left.D_{k}\right) /\left(S_{s}-D_{k}\right)$ ], where $S_{0}$ was the sample signal, with $S_{s}$ and $D_{k}$ defined as in the previous paragraph.

While sample processing was occurring, a plot of the analytical signal was displayed on the screen, in order to allow its visualization in real time. After the last event (step $\mathrm{f}$ ), the software returned to step (d), so as to start another analytical run.

To find the adequate volume of reagent solution, the assays were carried out using 20 sampling cycles for sample and varying from 1 up to 5 the On/Off switching event applied to minipumps $P_{1}$ and $P_{2}$ (step e). 


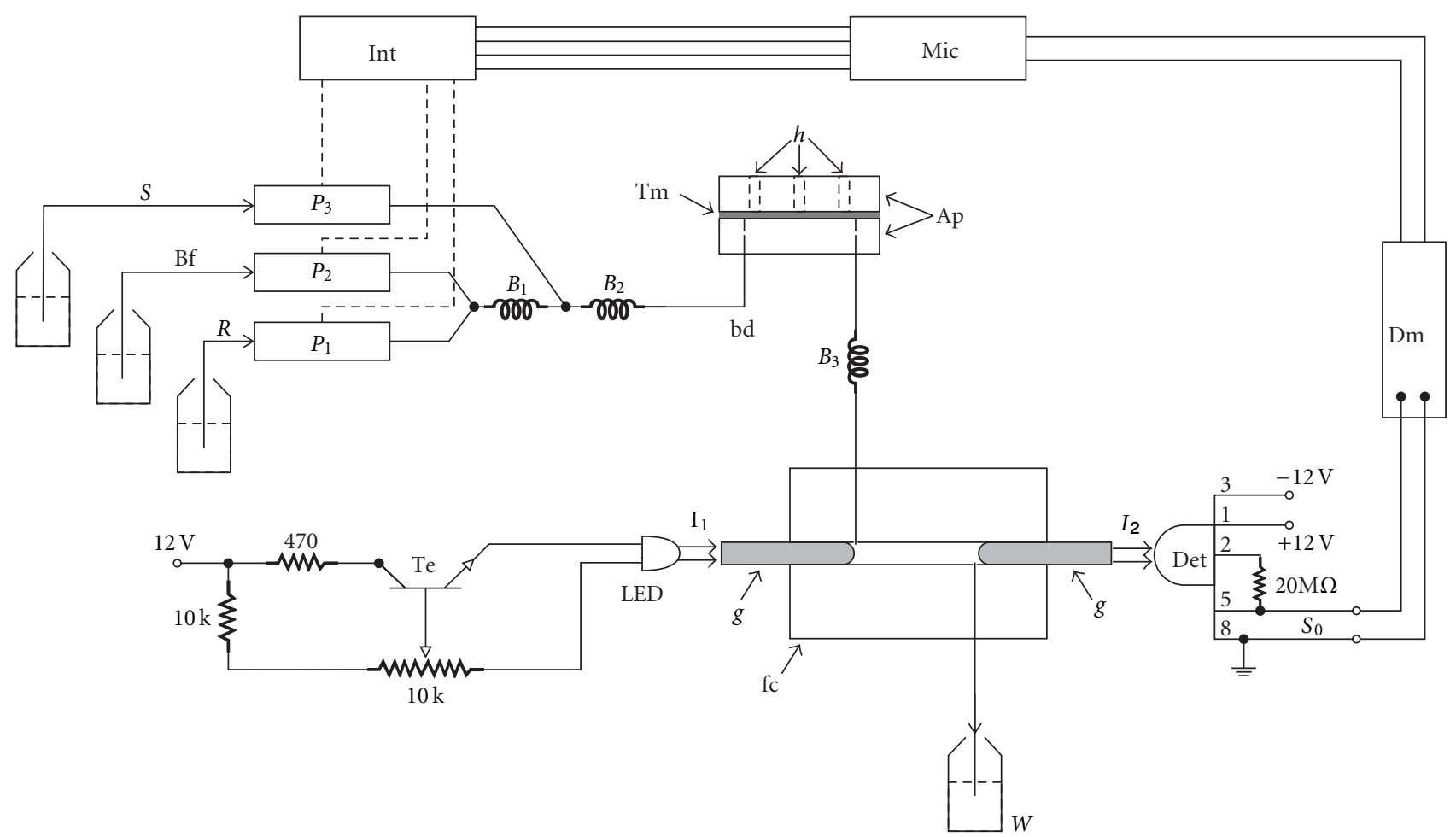

FIgure 1: Diagram of the flow analysis module. $S=$ sample or $\mathrm{ClO}^{-}$standard solution; $R=0.1 \mathrm{~g} \mathrm{~L}^{-1} \mathrm{LCV}$ solution; $\mathrm{Bf}=$ acetate buffer, pH 4.0; Int = homemade power driver interface; $\mathrm{Mic}=$ microcomputer; $\mathrm{Dm}=$ digital multimeter; $P_{1}, P_{2}$, and $P_{3}=$ solenoid minipumps; $B_{1}, B_{2}$, and $B_{3}=$ flow lines, Tygon tubing 40,15 , and $25 \mathrm{~cm}$ long, respectively, and $0.56 \mathrm{~mm}$ inner diameter; bd = bubble removing device; $\mathrm{Ap}=$ acrylic plates, length, width and thickness of 40,30 , and $10 \mathrm{~mm}$, respectively; $h=$ holes, $2.0 \mathrm{~mm}$ diameter; Tm $=$ Teflon membrane; fc $=$ cutaway of the flow cell; $W=$ waste; $g$ = glass cylinders, $30 \mathrm{~mm}$ length and $1.0 \mathrm{~mm}$ diameter; $\mathrm{LED}=\lambda_{\max }$ of $590 \mathrm{~nm}$, high bright (10,000 mcd); $\mathrm{Te}=$ transistor BC547; Det $=$ photodetector OPT301; $I_{1}$ and $I_{2}=$ electromagnetic radiation beam from LED and to detector, respectively; $S_{0}=$ signal output $(\mathrm{mV})$.

The assays described above were carried out using a chromogenic reagent solution with a concentration of $0.1 \mathrm{~g} \mathrm{~L}^{-1}$ LCV and a $1.0 \mathrm{mg} \mathrm{L}^{-1} \mathrm{ClO}^{-}$standard solution. To find the appropriate reagent concentration, experiments were performed applying 12 and 8 sampling cycles for sample and reagent solution, respectively. Maintaining the hypochlorite concentration at $1.0 \mathrm{mg} \mathrm{L}^{-1}$, the $\mathrm{LCV}$ concentration was varied from 0.02 up to $0.1 \mathrm{~g} \mathrm{~L}^{-1}$.

Aiming to prove the effectiveness of the proposed setup, a set of tap water samples was analyzed. To allow accuracy assessment, samples were also analyzed using a reference procedure [31]. In this procedure, hypochlorite in a $\mathrm{pH} 6.3$ medium reacts with the chromogenic reagent $\mathrm{N}, \mathrm{N}^{\prime}$-diethylp-phenylenediamine (DPD), which is oxidized to a redcolored semiquinonoid cationic radical $\left(\mathrm{DPD}^{*}\right)$ that was monitored at $520 \mathrm{~nm}$.

\section{Results and Discussion}

3.1. General Comments. According to Hatch [9] and Lambert et al. [13], the stoichiometric relationship of LCV oxidation by hypoiodous acid or iodine in acid medium results in the generation of two electrons for each oxidized molecule, as indicated by the equations shown below:

$$
\begin{gathered}
\mathrm{HIO}+\mathrm{LCV} \longrightarrow \mathrm{I}^{-}+\mathrm{CV}^{+}+\mathrm{H}_{2} \mathrm{O}, \\
\mathrm{I}^{2}+\mathrm{LCV} \longrightarrow 2 \mathrm{I}^{-}+\mathrm{CV}^{+}+\mathrm{H}^{+},
\end{gathered}
$$

where LCV is leuco crystal violet and $\mathrm{CV}^{+}$is the colored crystal violet specie.

Since LCV could be oxidized by hypochlorite, following a reaction mechanism similar to that described for HIO, one would expect that a relationship according to the equation shown below occurs:

$$
\mathrm{HClO}+\mathrm{LCV} \longrightarrow \mathrm{Cl}^{-}+\mathrm{CV}^{+}+\mathrm{H}_{2} \mathrm{O} .
$$

Preliminary assays carried out using hypochlorite working solutions showed that absorbance at $592 \mathrm{~nm}$ was directly proportional to hypochlorite concentration, thus this feature was employed to develop the analytical procedure.

Reduction of reagent consumption and waste generation are among the requisites necessary to attain the GAC recommendation $[18,19]$, and the volumes of solutions 
TABLE 1: Minipumps switching pattern.

\begin{tabular}{|c|c|c|c|c|c|c|}
\hline Step & Event & $P_{1}$ & $P_{2}$ & $P_{3}$ & Cycles & Volume $(\mu \mathrm{L})$ \\
\hline (a) & Filling flow lines & On & Off & Off & 30 & 360 \\
\hline (b) & Washing flow cell & Off & On & Off & 40 & 240 \\
\hline (c) & Photometer calibration & Off & Off & Off & 0 & - \\
\hline (d) & DPD and acetate buffer insertion & On & On & Off & 4 & 48 \\
\hline (e) & Sample insertion signal reading & Off & On & On & 12 & 144 \\
\hline (f) & Signal reading & Off & On & Off & 40 & 240 \\
\hline
\end{tabular}

The number 1 and 0 indicated that respective mini-pump is switched ON or OFF, respectively. Cycles indicate the selected number of times that each valve was switched On/Off.

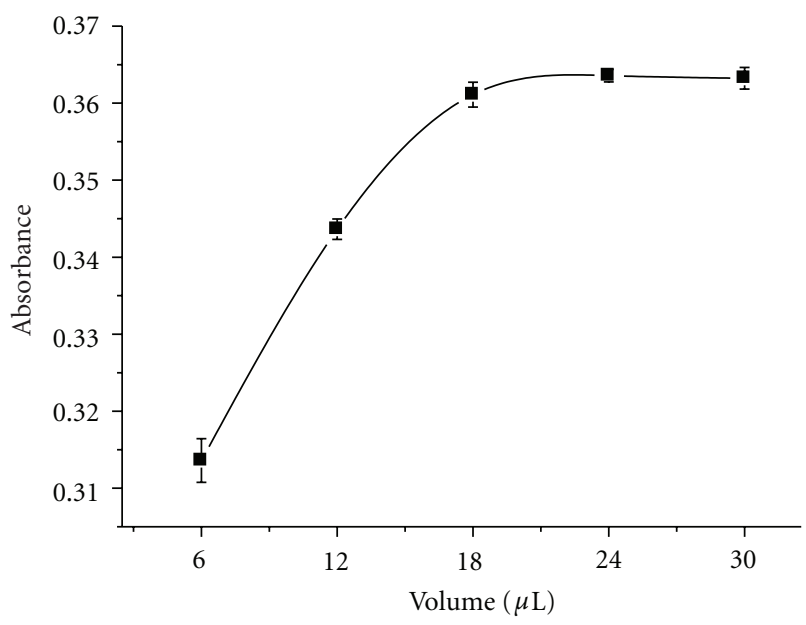

FIGURE 2: Effect of chromogenic reagent volume on the analytical signal.

delivered by the solenoid micropumps per stroke have been used to calculate reagent consumption and waste generation [28]. Nominally, the solenoid micropumps used in this work should deliver a solution volume of $8 \mu \mathrm{L}$ per stroke, nevertheless, in an earlier work, it was verified that volume delivered per stroke was lower than the expected value [28]. Thus, considering this fact, the volume of solution delivered by stroke under working condition was determined, and was done by applying for each micropump $10 \mathrm{On} / \mathrm{Off}$ pulses. The water volume was collected into a vial and weighted to determine the actual volume, which was found to be $6.0 \mu \mathrm{L}$ per stroke.

3.2. Effect of the Reagents Concentration. The effect concerning the LCV concentration was investigated using a $1.0 \mathrm{mg} \mathrm{L}^{-1} \mathrm{ClO}^{-}$standard solution and applying 12 and 8 sampling cycles for sample and reagent solution, respectively. The LCV concentration varied from 0.02 up to $0.10 \mathrm{~g} \mathrm{~L}^{-1}$. The absorbance increased up to a concentration of $0.08 \mathrm{~g} \mathrm{~L}^{-1}$ and showed a tendency to a constant value for higher concentration. Thus, the $0.10 \mathrm{~g} \mathrm{~L}^{-1}$ solution was selected, so as to assure an excess of reagent throughout the sample zone.

3.3. Effect of the LCV Solution Volume. The assays commented on in previous sections were carried out by inserting aliquots of both LCV and buffer solution, each one with

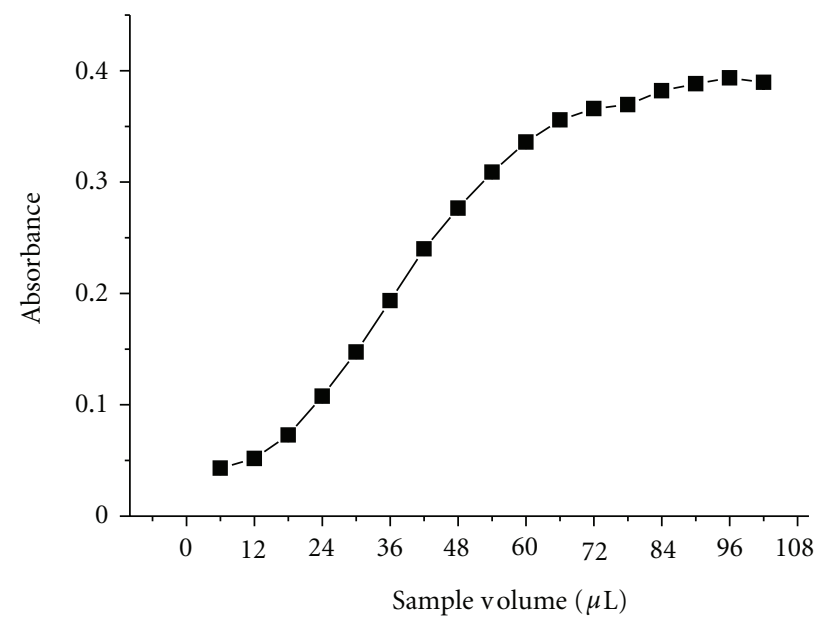

Figure 3: Effect of sample volume on the analytical signal. Standard solution $1.0 \mathrm{mg} \mathrm{L}^{-1} \mathrm{ClO}^{-} ; 24 \mu \mathrm{L}$ of reagent and buffer solution.

a volume of $48 \mu \mathrm{L}$ and an aliquot of sample solution with a volume of $72 \mu \mathrm{L}$. As is shown in Table 1 (step e), micropumps $P_{2}$ and $P_{3}$ were also switched On/Off 12 times, therefore, the volume of the sample zone was $144 \mu \mathrm{L}$. Aiming to minimize the reagent consumption, a set of experiments was carried out by varying the volume of the solution aliquot from 6 up to $30 \mu \mathrm{L}$, which was done by varying the number of sampling cycles (Table 1, step d) from 1 to 5 . The curve in Figure 2 shows that for volumes higher than $18 \mu \mathrm{L}$, the variation of the analytical signal was not significant. Thus, the volume of $24 \mu \mathrm{L}$ was selected as a compromise, in order to save reagent solution while, on the other hand, assuring a sufficient amount for allowing the reaction development to occur.

3.4. Effect of Sample Volume. With the objective of verify the effect caused by the sample volume on the analytical signal, assays were carried out by varying the volume of sample aliquot from 6 up to $102 \mu \mathrm{L}$, yielding the results shown in Figure 3. Analyzing this curve, we observe that for volumes higher than $66 \mu \mathrm{L}$, the signal increment decreased step by step. Thus, we would expect that signal magnitudes tend toward a constant. When sample volume varied within the range of 18 to $60 \mu \mathrm{L}$, a linear relationship $\left(R^{2}=0.998\right)$ was achieved. This behavior is quite different from that observed in the usual FIA system employing injection by loop. In order 
TABLE 2: System performance comparison.

\begin{tabular}{lcccc}
\hline Parameter & Proposed procedure & Reference [32] & Reference [33] & Reference [34] \\
\hline Linear equation & $A=0.069+0.281 \mathrm{C}$ & $A=0.011+0.170 \mathrm{C}$ & - & - \\
Working range $\left(\mathrm{mg} \mathrm{L}^{-1}\right)$ & $0.02-2.0$ & $0.6-4.8$ & $0.05-10.0$ & $2-14$ \\
Linear coefficient $\left(R^{2}\right)$ & 0.999 & 0.998 & 0.999 & 0.998 \\
$\mathrm{RSD}(\%), n=11$ & 1.0 & $<2.0$ & 0.9 & 1.4 \\
LOD, $3 \sigma\left(\mu \mathrm{g} \mathrm{L}^{-1}\right)$ & 6.0 & 600 & 30 & 510 \\
Determination per hour & 84 & 15 & 110 & 45 \\
Reagent consumption $*(\mu \mathrm{g})$ & 2.4 & 40 & 150 & 1300 \\
Effluent generation* $(\mu \mathrm{L})$ & 432 & 3430 & 1360 & 2200 \\
\hline
\end{tabular}

* Per determination.

to achieve a compromise between sensitivity and throughput, a sample volume of $72 \mu \mathrm{L}$ was selected.

3.5. Performance of the Proposed System. Once the operational conditions of the system were established, a set of assays was carried out, in order to verify the overall performance of the system. The results achieved are compared with other procedures and are summarized in Table 2. As we can see, the proposed procedure presented useful features: a wide linear response range, a low limit of detection, which was estimated as three times standard deviation of blank divided by the slope of the analytical curve, high throughput, low volume of waste generated, and low reagent consumption. Comparing these data with those presented in the referenced papers [32-34], we observe that, excepting throughput (see [33]), the results are highly favorable for the proposed system.

An additional assay was carried out in order to verify whether LCV also reacted with combined chlorine. The assay was done using two sets of standard solutions. The first one containing $1.0 \mathrm{mg} \mathrm{L}^{-1} \mathrm{ClO}^{-}$plus $1.0 \mathrm{mg} \mathrm{L}^{-1} \mathrm{NH}_{4}^{+}$ and $2.0 \mathrm{mg} \mathrm{L}^{-1} \mathrm{ClO}^{-}$plus $2.0 \mathrm{mg} \mathrm{L}^{-1} \mathrm{NH}_{4}^{+}$; the second one, prepared to contain equal $\mathrm{ClO}^{-}$concentration without ammonium. In the first case, absorbances generated processing both solutions were $\approx 97 \%$ lower than those observed when standard solutions were prepared without ammonium. Therefore, we could consider these results as an indication that the LCV does not reacted with combined chloride.

3.6. Sample Analysis. A set of tap water samples was analyzed, employing the operational conditions shown in Table 1, yielding the results shown in Table 3. In order to make accurate assessment, the samples were also analyzed using a reference method [30]. Student's paired $t$-test calculated for the values obtained by both procedures for the $95 \%$ confidence level was found to be 1.360 . Since the theoretical value is 2.447 , there is no significant difference at the $95 \%$ confidence level.

\section{Conclusions}

The performance of the proposed setup proved that multicommuted flow injection analysis (MCFA), implemented
TABLE 3: Comparison of results obtained by proposed procedure and the reference method.

\begin{tabular}{lcc}
\hline \multirow{2}{*}{ Sample } & \multicolumn{2}{c}{ Hypochlorite $\left(\mathrm{mg} \mathrm{L}^{-1}\right)$} \\
\hline A & Proposed & DPD [31] \\
B & $0.471 \pm 0.008$ & $0.462 \pm 0.005$ \\
C & $0.026 \pm 0.001$ & $0.026 \pm 0.001$ \\
D & $0.026 \pm 0.00$ & $0.027 \pm 0.001$ \\
E & $0.471 \pm 0.004$ & $0.428 \pm 0.005$ \\
F & $0.274 \pm 0.006$ & $0.270 \pm 0.005$ \\
\hline
\end{tabular}

Results are average of the four consecutive sample analyses. No significant difference at $95 \%$ confidence level, $t_{\text {tabled }}=2.447, t_{\text {calculated }}=1.360$.

employing solenoid minipumps to propel solutions, afforded facilities for downscaling the flow setup. Its reduced dimension allowed a drastic reduction of reagent consumption and waste generation, without any sacrificing of precision, accuracy, and throughput.

Although the LCV had been employed for many analytical purposes, it had not yet been used for hypochlorite determination. In this work, we proved that LCV can be used as a chromogenic reagent for the photometric determination of $\mathrm{ClO}^{-}$in tap water.

\section{Acknowledgments}

The authors acknowledge the CNPq, CAPES, FAPESP, PRONEX/FAPESB, and CNPq/INCTAA.

\section{References}

[1] S. Puget, N. Beno, C. Chabanet, E. Guichard, and T. ThomasDanguin, "Tap water consumers differ from non-consumers in chlorine flavor acceptability but not sensitivity," Water Research, vol. 44, no. 3, pp. 956-964, 2010.

[2] Y. Wang, L. Claeys, D. Van Der Ha, W. Verstraete, and N. Boon, "Effects of chemically and electrochemically dosed chlorine on Escherichia coli and Legionella beliardensis assessed by flow cytometry," Applied Microbiology and Biotechnology, vol. 87, no. 1, pp. 331-341, 2010.

[3] A. O. Al-Jasser, "Chlorine decay in drinking-water transmission and distribution systems: pipe service age effect," Water Research, vol. 41, no. 2, pp. 387-396, 2007. 
[4] Health Ministry of Brazil, "Regulation n. 518," March, 2004, http://dtr2001.saude.gov.br/sas/PORTARIAS/Port2004/GM/ GM-518.htm.

[5] R. Olivé-Monllau, J. Orozco, C. Fernández-Sánchez et al., "Flow injection analysis system based on amperometric thinfilm transducers for free chlorine detection in swimming pool waters," Talanta, vol. 77, no. 5, pp. 1739-1744, 2009.

[6] R. B. R. Mesquita, M. L. F. O. B. Noronha, A. I. L. Pereira et al., "Use of tetramethylbenzidine for the spectrophotometric sequential injection determination of free chlorine in waters," Talanta, vol. 72, no. 3, pp. 1186-1191, 2007.

[7] B. Saad, W. T. Wai, A. S. M. Ali, and M. I. Saleh, "Sequential flow injection determination of chlorine species using a triiodide-selective electrode detector," Analytical Sciences, vol. 22, no. 1, pp. 45-50, 2006.

[8] W. Qin, Z. Zhang, and S. Liu, "Flow-injection chemiluminescence sensor for the determination of free chlorine in tap water," Analytical Letters, vol. 30, no. 1, pp. 11-19, 1997.

[9] G. L. Hatch, "Hypoiodous acid, iodine, and iodide determination with leuco crystal violet and N-chlorosuccinimidesuccinimide reagents," Analytical Chemistry, vol. 56, no. 12, pp. 2238-2241, 1984.

[10] M. A. Kessick, J. Vuceta, and J. J. Morgan, "Spectrophotometric determination of oxidized manganese with leuco crystal violet," Environmental Science and Technology, vol. 6, no. 7, pp. 642-644, 1972.

[11] H. A. Mottola, B. E. Simpson, and G. Gorin, "Absorptiometric determination of hydrogen peroxide in submicrogram amounts with leuco crystal violet and peroxidase as catalyst," Analytical Chemistry, vol. 42, no. 3, pp. 410-411, 1970.

[12] O. Agrawal, G. Sunita, and V. K. Gupta, "A sensitive colorimetric method for the micro determination of iodine in marine water," Talanta, vol. 49, no. 4, pp. 923-928, 1999.

[13] J. L. Lambert, G. L. Hatch, and B. Mosier, "Iodide and iodine determination in the parts-per-billion range with leuco crystal violet and N-chlorosuccinimide-succinimide reagents," Analytical Chemistry, vol. 47, no. 6, pp. 915-916, 1975.

[14] G. H. Ayres and W. T. Bolleter, "Spectrophotometric determination of iridium with leuco-crystal violet," Analytical Chemistry, vol. 29, no. 1, pp. 72-75, 1957.

[15] F. R. P. Rocha, J. A. Nóbrega, and O. Fatibello Filho, "Flow analysis strategies to greener analytical chemistry-an overview," Green Chemistry, vol. 3, no. 5, pp. 216-220, 2001.

[16] S. Armenta, S. Garrigues, and M. de la Guardia, "Green Analytical Chemistry," TrAC-Trends in Analytical Chemistry, vol. 27, no. 6, pp. 497-511, 2008.

[17] S. Garrigues, S. Armenta, and M. D. L. Guardia, "Green strategies for decontamination of analytical wastes," TrACTrends in Analytical Chemistry, vol. 29, pp. 592-601, 2010.

[18] N. O. Soto, B. Horstkotte, J. G. March, P. L. L. D. Alba, L. L. Martínez, and V. C. Martín, "An environmental friendly method for the automatic determination of hypochlorite in commercial products using multisyringe flow injection analysis," Analytica Chimica Acta, vol. 611, no. 2, pp. 182-186, 2008.

[19] W. R. Melchert and F. R. P. Rocha, "A greener and highly sensitive flow-based procedure for carbaryl determination exploiting long pathlength spectrophotometry and photochemical waste degradation," Talanta, vol. 81, no. 1-2, pp. 327333, 2010.

[20] B. F. Reis, M. F. Gine, E. A. G. Zagatto, J. L. F. C. Lima, and R. A. Lapa, "Multicommutation in flow analysis. Part 1. Binary sampling: concepts, instrumentation and spectrophotometric determination of iron in plant digests," Analytica Chimica Acta, vol. 293, no. 1-2, pp. 129-138, 1994.
[21] F. R. P. Rocha, P. B. Martelli, and B. F. Reis, "An improved flow system for spectrophotometric determination of anions exploiting multicommutation and multidetection," Analytica Chimica Acta, vol. 438, no. 1-2, pp. 11-19, 2001.

[22] J. A.E. Carvalhido, A. A. Almeida, A. N. Araújo, and M. C.B.S.M. Montenegro, "A reflectance flow-through thionine sol-gel sensor for the determination of Se(IV)," Analytical Sciences, vol. 26, no. 6, pp. 665-669, 2010.

[23] A. M. Serra, J. M. Estela, B. Coulomb, J. L. Boudenne, and V. Cerdà, "Solid phase extraction-multisyringe flow injection system for the spectrophotometric determination of selenium with 2,3-diaminonaphthalene," Talanta, vol. 81, no. 1-2, pp. 572-577, 2010.

[24] E. R. G. O. Rodrigues, R. A. S. Lapa, and J. L. F. C. Lima, "A multicommutated flow system based on an opened-loop with micropump propulsion," Analytical Letters, vol. 40, no. 8, pp. 1632-1645, 2007.

[25] C. M. C. Infante, A. Morales-Rubio, M. de la Guardia, and F. R. P. Rocha, "A multicommuted flow system with solenoid micro-pumps for paraquat determination in natural waters," Talanta, vol. 75, no. 5, pp. 1376-1381, 2008.

[26] A. F. Lavorante, A. Morales-Rubio, M. De La Guardia, and B. F. Reis, "Micro-pumping flow system for spectrophotometric determination of anionic surfactants in water," Analytical and Bioanalytical Chemistry, vol. 381, no. 6, pp. 1305-1309, 2005.

[27] M. A. Feres and B. F. Reis, "A downsized flow set up based on multicommutation for the sequential photometric determination of iron(II)/iron(III) and nitrite/nitrate in surface water," Talanta, vol. 68, no. 2, pp. 422-428, 2005.

[28] S. S. Borges, J. D. S. Peixoto, M. A. Feres, and B. F. Reis, "Downscaling a multicommuted flow injection analysis system for the photometric determination of iodate in table salt," Analytica Chimica Acta, vol. 668, no. 1, pp. 3-7, 2010.

[29] G. H. Jeffery, J. Bassett, J. Mendham, and R. C. Denney, Vogel's Quantitative Chemical Analysis, Longman, Harlow, UK, 1989.

[30] E. Ródenas-Torralba, F. R. P. Rocha, B. F. Reis, A. MoralesRubio, and M. De La Guardia, "Evaluation of a multicommuted flow system for photometric environmental measurements," Journal of Automated Methods and Management in Chemistry, vol. 2006, Article ID 20384, pp. 1-9, 2006.

[31] APHA, AWWA, and WPCF, Standard Methods for the Examination of Water and Wastewater, APHA, Washington, DC, USA, 1985.

[32] R. B. R. Mesquita and A. O. S. S. Rangel, "Gas diffusion sequential injection system for the spectrophotometric determination of free chlorine with o-dianisidine," Talanta, vol. 68, no. 2, pp. 268-273, 2005.

[33] K. K. Verma, A. Jain, and A. Townshend, "Determination of free and combined residual chlorine by flow-injection spectrophotometry," Analytica Chimica Acta, vol. 261, no. 12, pp. 233-240, 1992.

[34] F. H. Salami, V. G. Bonifácio, G. G. De Oliveira, and O. Fatibello-Filho, "Spectrophotometric multicommutated flow system for the determination of hypochlorite in bleaching products," Analytical Letters, vol. 41, no. 17, pp. 3187-3197, 2008. 


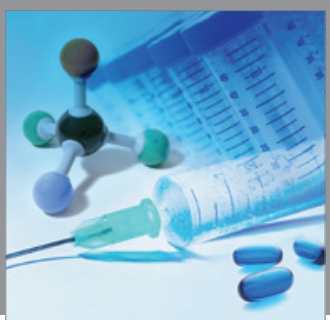

International Journal of

Medicinal Chemistry

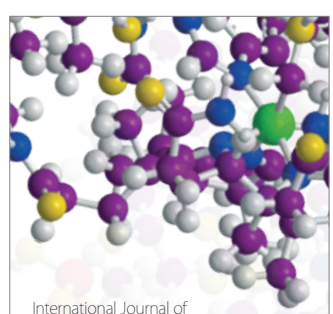

Carbohydrate Chemistry

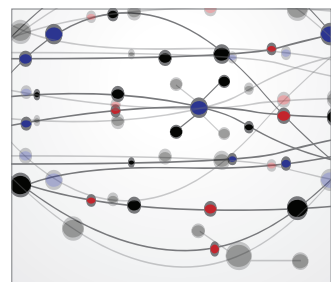

The Scientific World Journal
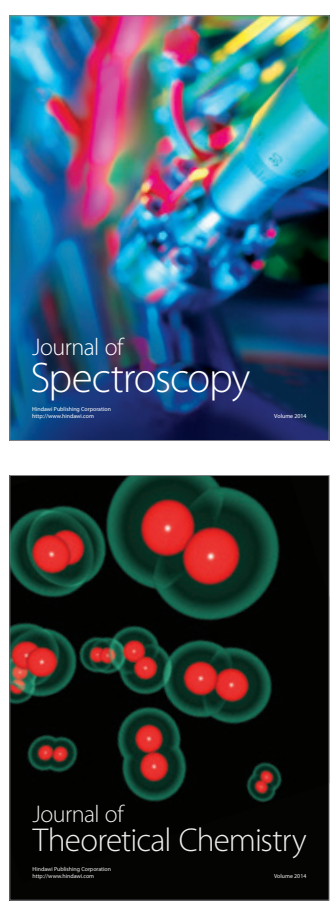
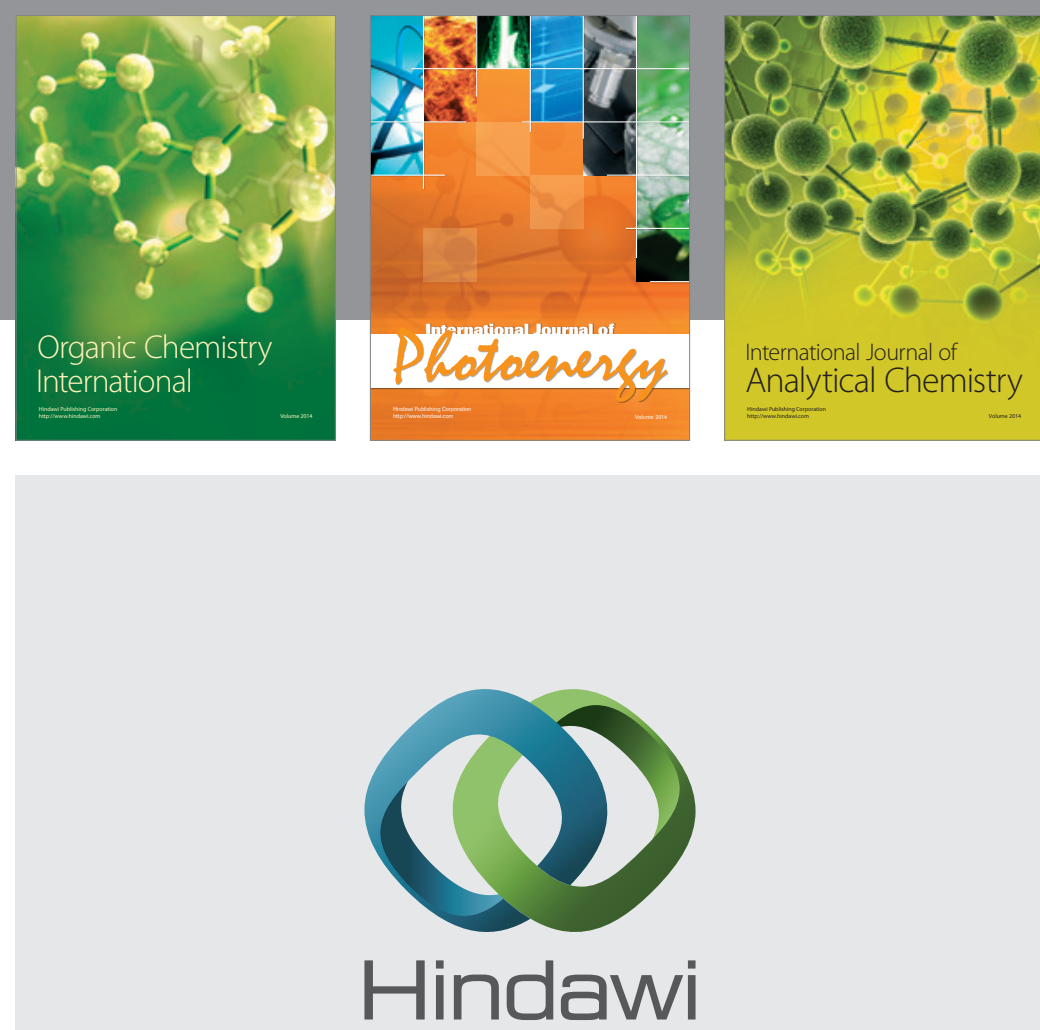

Submit your manuscripts at

http://www.hindawi.com
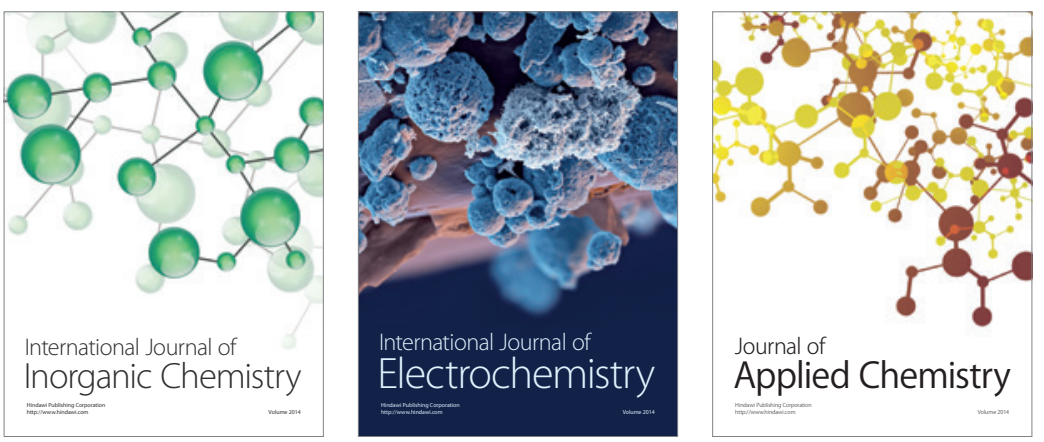

Journal of

Applied Chemistry
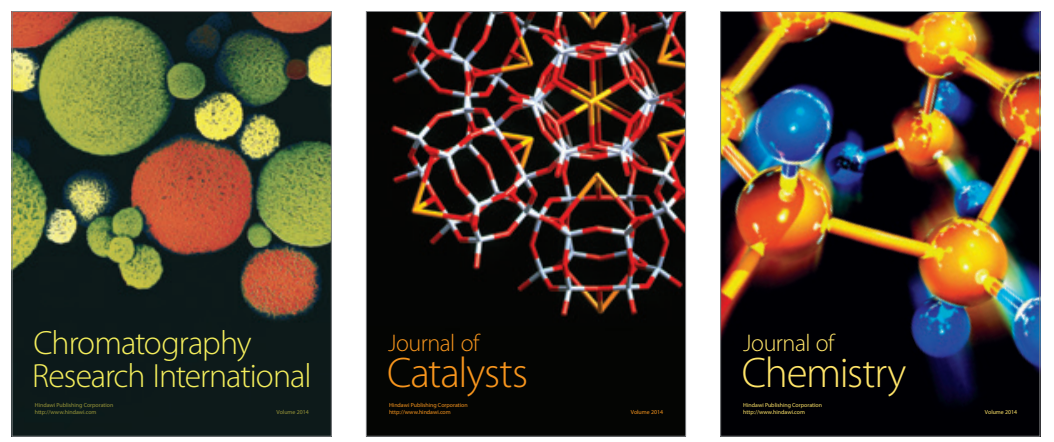
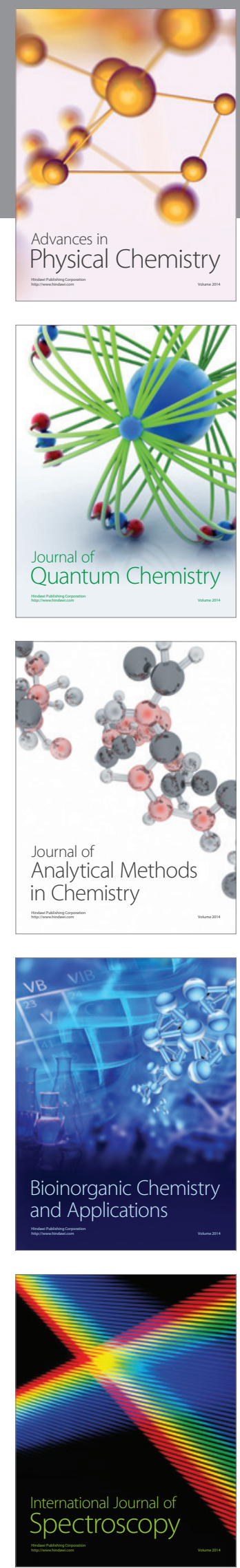